(2) Open Access Full Text Article

ORIGINAL RESEARCH

\title{
Altered status of programmed death-ligand I after recurrence in resected lung adenocarcinoma patients
}

This article was published in the following Dove Press journal:

OncoTargets and Therapy

6 April 2017

Number of times this article has been viewed

\section{Jun Chen \\ Hui Li \\ Ronglin Pang \\ Jia Huang}

Department of Chemoradiotherapy, Yinzhou Hospital Affiliated to Ningbo University School of Medicine,

Ningbo, People's Republic of China
Correspondence: Jun Chen Department of Chemoradiotherapy, Yinzhou Hospital Affiliated to Ningbo University School of Medicine, East Baizhang Road, Ningbo 315100,

People's Republic of China

Tel +86574870I 6888

Fax +86 57487016888

Email chenjunningbo@।63.com
Purpose: Programmed death-ligand 1 (PD-L1) is found to be overexpressed in non-small cell lung cancer. The present study intended to evaluate the status of PD-L1 expression in patients with resection and recurrent lung adenocarcinoma.

Patients and methods: Matched resection and recurrent tumor samples were harvested from 65 lung adenocarcinoma patients. Immunohistochemistry was used to evaluate the status of PD-L1 expression. Kaplan-Meier method was used for survival analysis.

Results: A total of 65 patients of lung adenocarcinoma were enrolled. They underwent complete resection and had recurrence after adjuvant treatment. PD-L1 expression was identified in $43.1 \%$ $(28 / 65)$ of resection samples vs 55.4\% (36/65) of recurrent samples. Ten patients shifted from negative to positive, whereas another two samples showed the opposite. Patients with PD-L1 expression showed worse disease-free survival than the PD-L1-negative counterparts. The expression of PD-L1 in recurrent samples was a significant favorable factor for epidermal growth factor receptor tyrosine kinase inhibitors ( $E G F R$-TKIs) (11.2 vs 8.2 months, $P=0.030$ ).

Conclusion: The status of PD-L1 expression may alter between resection and recurrent samples. Also, the status of PD-L1 expression after recurrence is a better prognostic factor for EGFR-TKIs.

Keywords: programmed death-ligand 1, overexpression, lung adenocarcinoma, survival

\section{Introduction}

Non-small cell lung cancer accounts for $>80 \%$ of all lung carcinomas and lung adenocarcinoma is predominant. ${ }^{1}$ At present, chemotherapy, radiotherapy, molecular therapy and surgery are the major treatment modalities for lung cancer treatment. ${ }^{2}$ However, most patients remain resistant to treatment with a median survival time of $<2$ years. $^{3-7}$

It is well known that immune therapy based on programmed death-1 (PD-1) and its ligand PD-L1 shows promising efficacy. ${ }^{8,9}$ The progression-free survival (PFS) was longer in patients on immunotherapy than those on chemotherapy based on high-expression PD-L1. ${ }^{10}$ PD-L1 has been identified as a useful biomarker for immunotherapy. Chemotherapy could alter the status of PD-L1 expression in squamous cell carcinoma. ${ }^{11}$ However, PD-L1 status is not thoroughly examined for lung adenocarcinoma in resection and recurrent samples.

The present study was intended to detect the PD-L1 expression status in resection and recurrent samples and validate its clinical value in lung adenocarcinoma. 


\section{Materials and methods}

\section{Patient selection}

During the period 2009-2015, 65 patients with pathologically confirmed lung adenocarcinoma were recruited from Yinzhou Hospital of Zhejiang Province. The inclusion criteria were as follows: 1) pathologically proven primary lung adenocarcinoma with resection and recurrent samples and 2) no prior local treatment in recurrent samples. Histologic typing was confirmed as lung adenocarcinoma according to the 2004 World Health Organization classification scheme. Also, TNM stage was determined according to the 2009 criteria. The Ethics Committee of Yinzhou Hospital approved this study (IRB-2015-027), and written informed consent was obtained from each participant.

\section{Immunohistochemical analysis of PD-LI expression}

Analysis of PD-L1 expression was performed on 4-6 $\mu \mathrm{m}$ thick, formalin-fixated, paraffin-embedded tissue with immunohistochemical staining. PD-L1 from Proteintech Group Inc. (Chicago, IL, USA) was utilized. UltraVision Quanto Detection System (Thermo Fisher Scientific, Waltham, MA, USA) was used for detecting PD-L1 expression according to the manufacturer's instructions.

Semi-quantitative H-score (a maximal value of 300 corresponding to $100 \%$ of tumor cells staining positive for PD-L1 with an overall staining intensity score of 3) was determined by multiplying the percentage of stained cells by an intensity score ( 0 , absent; 1 , weak; 2 , moderate; 3 , strong). A $5 \%$ proportion of membranous staining of tumor cells with $\mathrm{H}$-score $\geq 5$ was designated as the cutoff for PD-L1 positivity. Three independent pathologists assessed the expression of PD-L1 status.

\section{Efficacy evaluation}

Tumor efficacy was evaluated according to the Response Evaluation Criteria in Solid Tumors (RECIST 1.1). Tumor responses included complete response, partial response, stable disease and progressive disease. Also, disease control rate was defined as a combination of objective responses and stabilization. The median follow-up period was 38 (13-71) months. The last follow-up date was October 31, 2016.

\section{Statistical analyses}

Chi-squared test was used for evaluating the relationship between clinical characteristics and status of PD-L1 expression. Survival curves were calculated by the KaplanMeier method. Statistical analysis was performed with SPSS
16 software (SPSS Inc., Chicago, IL, USA). $P<0.05$ was deemed as statistically significant.

\section{Results}

\section{Clinical characteristics}

A total of 65 patients of lung adenocarcinoma were recruited. There were 37 males and 28 females with a median age of 62 (35-75) years. The smoking status was former/current $(n=34)$ and never ( $\mathrm{n}=31)$ smokers. All patients underwent complete resection. Their pathologic stages were I $(n=19)$, II $(n=15)$ and IIIA ( $\mathrm{n}=32)$. Among the patients, 56 patients received adjuvant treatment, including chemotherapy $(n=25)$, radiotherapy $(n=3)$ and chemoradiotherapy $(n=28)$. Their clinicopathologic characteristics are summarized in Table 1.

\section{PD-LI status in resection and recurrent samples}

As for PD-L1 expression, 28 (43.1\%) patients were positive in resection samples vs 36 in recurrent samples. Ten patients shifted from negative to positive, whereas another two samples showed the opposite ( $P=0.005$; Table 2 ).

No correlations existed in gender, age, smoking status or status of PD-L1 expression. Similarly, there was no correlation between clinicopathologic characteristics and PD-L1 expression in recurrent samples. The correlations

Table I Clinical characteristics of the patient population ( $N=65)$

\begin{tabular}{ll}
\hline Variable & Number \\
\hline Gender & 37 \\
Male & 28 \\
Female & \\
Age, years & 62 \\
Median & 47 \\
$\quad<65$ & 18 \\
$\geq 65$ & \\
Smoking status & 31 \\
Never & 34 \\
Former/current & \\
Pathological stage after surgery & 33 \\
I+ II & 32 \\
IIIA & \\
EGFR status & 28 \\
Mutation & 24 \\
Wild type & 13 \\
Unknown & \\
PD-LI expression in resected samples & 28 \\
Positive & 37 \\
Negative \\
PD-LI expression in recurrence samples \\
Positive & \\
Negative & 36 \\
\hline
\end{tabular}

Abbreviations: EGFR, epidermal growth factor receptor; PD-LI, programmed death-ligand $\mathrm{I}$. 
Table 2 Clinical characteristics of patients with altered PD-LI expression

\begin{tabular}{|c|c|c|c|c|c|c|c|}
\hline \multirow[t]{2}{*}{ Case } & \multirow{2}{*}{$\begin{array}{l}\text { Genderl } \\
\text { age (years) }\end{array}$} & \multirow{2}{*}{$\begin{array}{l}\text { Pathological } \\
\text { stage }\end{array}$} & \multirow{2}{*}{$\begin{array}{l}\text { Smoking } \\
\text { status }\end{array}$} & \multicolumn{2}{|l|}{ PD-LI expression } & \multirow{2}{*}{$\begin{array}{l}\text { Disease-free } \\
\text { survival, months }\end{array}$} & \multirow{2}{*}{$\begin{array}{l}\text { Overall survival, } \\
\text { months }\end{array}$} \\
\hline & & & & Resected samples & Recurrence samples & & \\
\hline I & $M / 6 \mathrm{I}$ & IIIA & Former & Positive & Negative & 11.5 & 37.9 \\
\hline 2 & $M / 55$ & IIIA & Never & Positive & Negative & 20.0 & 45.5 \\
\hline 3 & $M / 67$ & IIIA & Former & Negative & Positive & 26.0 & 55.0 \\
\hline 4 & $M / 59$ & IIB & Former & Negative & Positive & 19.0 & 38.0 \\
\hline 5 & $M / 52$ & IIIA & Current & Negative & Positive & 7.0 & 21.0 \\
\hline 6 & $M / 7 I$ & IB & Former & Negative & Positive & 39.0 & 57.2 \\
\hline 7 & $\mathrm{~F} / 60$ & IIIA & Never & Negative & Positive & 12.5 & 43.0 \\
\hline 8 & $M / 63$ & $\| \mathrm{A}$ & Never & Negative & Positive & 33.0 & $49.0+$ \\
\hline 9 & $F / 66$ & IB & Never & Negative & Positive & 41.5 & $61.6+$ \\
\hline 10 & $M / 5 I$ & IIIA & Current & Negative & Positive & 16.0 & 36.5 \\
\hline 11 & $F / 38$ & IIB & Current & Negative & Positive & 13.3 & 35.2 \\
\hline 12 & $F / 5 I$ & IIIA & Never & Negative & Positive & 14.5 & 55.4 \\
\hline
\end{tabular}

Abbreviation: PD-LI, programmed death-ligand I.

between PD-L1 expression and clinical characteristics are summarized in Table 3.

\section{PD-LI expression and gene mutations}

Among the patients, the expression of epidermal growth factor receptor $(E G F R)$ and $A L K$ was detected in 52 patients. There were $28 E G F R$-mutant and 24 wild-type patients. Four harbored $A L K$ rearrangement and 48 were $A L K$ negative. The results of gene mutations were based on resection samples. The frequencies of PD-L1 expression were $66.7 \%$ and $42.9 \%$ in $E G F R$-mutant and wild-type patients, respectively $(P=0.08)$. No correlations existed between PD-L1 expression and $A L K$ rearrangements $(P=0.72)$.

\section{Treatment}

All the patients had a postoperative onset of recurrence or metastasis. The median values of disease-free survival and overall survival were 22.0 months ( $95 \%$ confidence interval: 19.1-26.2) and 37.1 months (95\% confidence interval: 34.0-39.4), respectively. All recurrences were treated. All 28 EGFR-mutant patients received EGFR-TKIs. According to the status of PD-L1 expression in recurrent samples, a longer PFS was observed in PD-L1-positive than PD-L1negative patients (11.2 vs 8.2 months, $P=0.030$; Figure 1 ). Also, 55 patients received first-line chemotherapy. No correlations of efficacy difference existed between PD-L1positive and PD-L1-negative patients (4.3 vs 4.6 months, $P=0.57)$.

\section{Survival analyses}

Based upon PD-L1 expression in resection samples, a trend of longer disease-free survival existed in PD-L1-negative than PD-L1-positive patients ( 23.0 vs 18.8 months, $P=0.01$; Figure 2). However, there was no significant difference in

Table 3 Correlation between PD-LI expression and clinical characteristics

\begin{tabular}{|c|c|c|c|c|c|c|}
\hline \multirow[t]{2}{*}{ Variable } & \multicolumn{3}{|c|}{ Resected samples } & \multicolumn{3}{|c|}{ Recurrence samples } \\
\hline & PD-LI positive & PD-LI negative & $P$-value & PD-LI positive & PD-LI negative & $P$-value \\
\hline Gender & & & 0.64 & & & 0.45 \\
\hline Male & 15 & 22 & & 19 & 18 & \\
\hline Female & 13 & 15 & & 17 & II & \\
\hline Age (years) & & & 0.21 & & & 0.049 \\
\hline$<65$ & 18 & 29 & & 22 & 25 & \\
\hline$\geq 65$ & 10 & 8 & & 14 & 4 & \\
\hline Smoking status & & & 0.49 & & & 0.56 \\
\hline Never & 12 & 19 & & 16 & 15 & \\
\hline Former/current & 16 & 18 & & 20 & 14 & \\
\hline Pathologic stage & & & 0.16 & & & 0.44 \\
\hline$I+I I$ & 17 & 16 & & NA & NA & NA \\
\hline IIIA & II & 21 & & NA & NA & NA \\
\hline EGFR mutation & & & 0.086 & & & \\
\hline Yes & 16 & 12 & & NA & NA & NA \\
\hline No & 8 & 16 & & NA & NA & NA \\
\hline
\end{tabular}

Abbreviations: EGFR, epidermal growth factor receptor; NA, not applicable; PD-LI, programmed death-ligand I. 


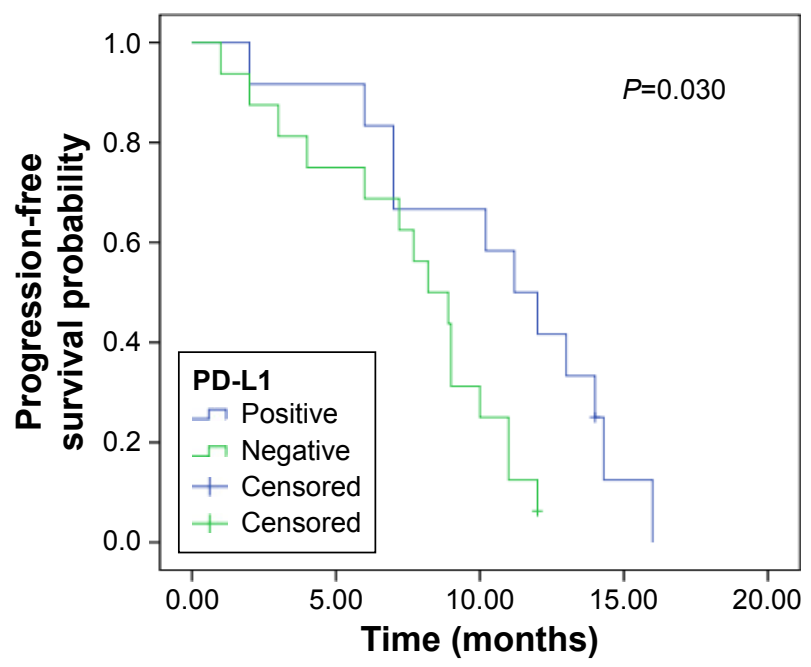

Figure I Progression-free survival of EGFR-TKIs in EGFR-mutant patients according to the status of PD-LI expression in recurrent samples.

Abbreviations: EGFR, epidermal growth factor receptor; PD-LI, programmed death-ligand I; TKIs, tyrosine kinase inhibitors.

overall survival according to the status of PD-L1 expression in resection samples (39.0 vs 34.0 months, $P=0.225$ ).

Similarly, no survival difference existed in recurrent samples between PD-L1-positive and PD-L1-negative groups (39.0 vs 34.5 months, $P=0.226$ ).

\section{Discussion}

The status of PD-L1 expression might alter after recurrence in some completely resected lung adenocarcinoma patients. The expression of PD-L1 became upregulated in recurrent samples. The status of PD-L1 after recurrence could better

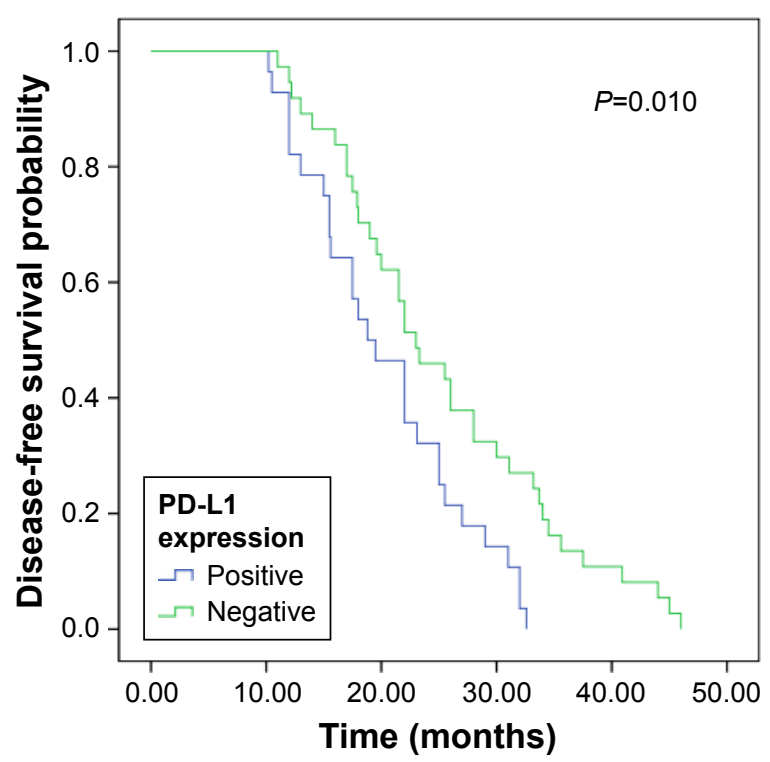

Figure 2 Comparison of disease-free survival based upon the status of PD-LI expression in resection lung adenocarcinoma samples. Abbreviation: PD-LI, programmed death-ligand I. predict the favorable efficacy of EGFR-TKIs. To the best of our knowledge, this was the first study of detecting differences between resection and recurrent samples in lung adenocarcinoma patients.

Many solid carcinomas were found to show overexpression of PD-L1.${ }^{12-16}$ It is well known that gene status might be affected by chemotherapy. ${ }^{17}$ However, the status of PD-L1 could be altered over time. PD-L1 status might alter before and after dosing of EGFR-TKIs in lung adenocarcinoma patients. ${ }^{18}$ Also, the magnitude of PD-L1 expression increased after chemotherapy in lung squamous cell carcinoma patients. ${ }^{11}$ In the present study, the frequency of PD-L1 expression increased in several recurrent samples. One reason for this might be an alteration of immune microenvironment after recurrence. Also, it was due to heterogeneity of tumors between resection and recurrent samples. Last but not least, most patients received adjuvant chemotherapy or radiotherapy, thus affecting PD-L1 expression partially. Because of inconstancy of PD-L1 expression in resection and recurrent samples, the status of PD-L1 expression should be remonitored in patients with recurrent or metastatic samples.

PD-L1 serves as a favorable biomarker for the efficacy of EGFR-TKIs, ${ }^{19}$ since EGFR-TKIs can inhibit tumor cell viability and indirectly enhance antitumor immunity through downregulation of PD-L $1 .^{20}$ In the present study, a longer PFS existed in PD-L1-positive patients than the negative counterparts. As concluded from previous and present studies, PD-L1 expression might affect the clinical efficacy of EGFR-TKIs. Prospective studies with a larger number of patients should be performed.

\section{Limitations}

The present study had some inherent limitations. First, it was retrospective in nature, and the sample size was too small. Second, use of only one antibody might have influenced the frequency of PD-L1 expression. Third, only $28 E G F R$-mutant patients received $E G F R$-TKIs, so few cases were available for efficacy analysis. Thus, our results should be validated by future studies of a larger sample size. However, our results may carry clinical implications for immunotherapy in lung adenocarcinoma patients.

\section{Conclusion}

PD-L1 expression may be upregulated after recurrence in resection lung adenocarcinoma patients. Also, PD-L1 may be a useful biomarker for predicting the efficacy of EGFR-TKIs. 


\section{Acknowledgment}

This work was supported by a grant from the Natural Science

Foundation of Ningbo (number 2012A610199).

\section{Disclosure}

The authors report no conflicts of interest in this work.

\section{References}

1. Zheng R, Zeng H, Zuo T, et al. Lung cancer incidence and mortality in China, 2011. Thorac Cancer. 2016;7(1):94-99.

2. Song Z, Shao L, Lin B, Zhang Y. Single-agent chemotherapy compared with combination chemotherapy as second-line treatment in extensivestage small cell lung cancer: a retrospective analysis. Clin Transl Oncol. 2013;15(10):843-848.

3. Levy B, Saxena A, Schneider BJ. Systemic therapy for small cell lung cancer. J Natl Compr Canc Netw. 2013;11(7):780-787.

4. Lee CK, Wu YL, Ding PN, et al. Impact of specific epidermal growth factor receptor (EGFR) mutations and clinical characteristics on outcomes after treatment with EGFR tyrosine kinase inhibitors versus chemotherapy in EGFR-mutant lung cancer: a meta-analysis. $J$ Clin Oncol. 2015;33(17):1958-1965.

5. Han JY, Park K, Kim SW, et al. First-SIGNAL: first-line single-agent iressa versus gemcitabine and cisplatin trial in never-smokers with adenocarcinoma of the lung. J Clin Oncol. 2012;30(10):1122-1128.

6. Zhou C, Wu YL, Chen G, et al. Erlotinib versus chemotherapy as first-line treatment for patients with advanced EGFR mutation-positive non-small-cell lung cancer (OPTIMAL, CTONG-0802): a multicentre, open-label, randomised, phase 3 study. Lancet Oncol. 2011;12(8): 735-742.

7. Mitsudomi T, Morita S, Yatabe Y, et al; West Japan Oncology Group. Gefitinib versus cisplatin plus docetaxel in patients with non-small-cell lung cancer harbouring mutations of the epidermal growth factor receptor (WJTOG3405): an open label, randomised phase 3 trial. Lancet Oncol. 2010;11(2):121-128.

8. Borghaei H, Paz-Ares L, Horn L, et al. Nivolumab versus docetaxel in advanced nonsquamous non-small-cell lung cancer. $N$ Engl J Med. 2015;373(17):1627-1639.
9. Brahmer JR, Tykodi SS, Chow LQ, et al. Safety and activity of antiPD-L1 antibody in patients with advanced cancer. N Engl J Med. 2012; 366(26):2455-2465.

10. Reck M, Rodríguez-Abreu D, Robinson AG, et al. Pembrolizumab versus chemotherapy for PD-L1-positive non-small-cell lung cancer. N Engl J Med. 2016;375(19):1823-1833.

11. Song Z, Yu X, Zhang Y. Altered expression of programmed death-ligand 1 after neo-adjuvant chemotherapy in patients with lung squamous cell carcinoma. Lung Cancer. 2016;99:166-171.

12. Song Z, Yu X, Cheng G, Zhang Y. Programmed death-ligand 1 expression associated with molecular characteristics in surgically resected lung adenocarcinoma. $J$ Transl Med. 2016;14(1):188.

13. Ohigashi $Y$, Sho M, Yamada $Y$, et al. Clinical significance of programmed death-1 ligand-1 and programmed death-1 ligand-2 expression in human esophageal cancer. Clin Cancer Res. 2005;11(8):2947-2953.

14. Thompson RH, Gillett MD, Cheville JC, et al. Costimulatory B7-H1 in renal cell carcinoma patients: indicator of tumor aggressiveness and potential therapeutic target. Proc Natl Acad Sci U S A. 2004;101(49): 17174-17179.

15. Ishii H, Azuma K, Kawahara A, et al. Significance of programmed cell death-ligand 1 expression and its association with survival in patients with small cell lung cancer. $J$ Thorac Oncol. 2015;10(3):426-430.

16. Ali HR, Glont SE, Blows FM, et al. PD-L1 protein expression in breast cancer is rare, enriched in basal-like tumours and associated with infiltrating lymphocytes. Ann Oncol. 2015;26:1488-1493.

17. Bai $\mathrm{H}$, Wang $\mathrm{Z}$, Chen $\mathrm{K}$, et al. Influence of chemotherapy on EGFR mutation status among patients with non-small-cell lung cancer. J Clin Oncol. 2012;30(25):3077-3083.

18. Gainor JF, Sequist L, Shaw AT, et al. Clinical correlation and frequency of programmed death ligand-1 (PD-L1) expression in EGFR-mutant and ALK-rearranged non-small cell lung cancer (NSCLC). J Clin Oncol. 2015;33 (suppl):Abstract 8012.

19. Lin C, Chen X, Li M, et al. Programmed death-ligand 1 expression predicts tyrosine kinase inhibitor response and better prognosis in a cohort of patients with epidermal growth factor receptor mutation-positive lung adenocarcinoma. Clin Lung Cancer. 2015;16(5):e25-e35.

20. Chen N, Fang W, Zhan J, et al. Upregulation of PD-L1 by EGFR activation mediates the immune escape in EGFR-driven NSCLC: implication for optional immune targeted therapy for NSCLC patients with EGFR mutation. J Thorac Oncol. 2015;10(6):910-923.
OncoTargets and Therapy

\section{Publish your work in this journal}

OncoTargets and Therapy is an international, peer-reviewed, open access journal focusing on the pathological basis of all cancers, potential targets for therapy and treatment protocols employed to improve the management of cancer patients. The journal also focuses on the impact of management programs and new therapeutic agents and protocols on

\section{Dovepress}

patient perspectives such as quality of life, adherence and satisfaction. The manuscript management system is completely online and includes a very quick and fair peer-review system, which is all easy to use. Visit http://www.dovepress.com/testimonials.php to read real quotes from published authors. 